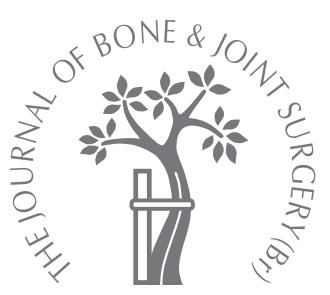

K. Higashino,

K. Sairyo,

S. Katoh,

S. Nakano,

T. Enishi,

N. Yasui

From The University

of Tokushima,

Tokushima, Japan

\title{
The effect of rheumatoid arthritis on the anatomy of the female cervical spine
}

\author{
A RADIOLOGICAL STUDY
}

- K. Higashino, $\mathrm{MD}, \mathrm{PhD}$,

Assistant Professor

I. K. Sairyo, MD, PhD,

Associate Professor

S. Katoh, MD, PhD, Associate

Professor

S. Nakano, MD, PhD,

Associate Professor

n. T. Enishi, MD, Orthopaedic

Surgeon

N. Yasui, MD, PhD, Professor and Chairman

Department of Orthopedics,

School of Medicine

The University of Tokushima,

3-18-15 Kuramoto, Tokushima

770-8503, Japan.

Correspondence should be sent to Professor N. Yasui; e-mail: nyasui@clin.med.tokushimau.ac.jp

(C)2009 British Editorial Society of Bone and Joint Surgery doi:10.1302/0301-620X.91B8 $22300 \$ 2.00$

$J$ Bone Joint Surg [Br] 2009;91-B:1058-63.

Received 13 January 2009;

Accepted after revision 20

March 2009

The effect of rheumatoid arthritis on the anatomy of the cervical spine has not been clearly documented. We studied 129 female patients, 90 with rheumatoid arthritis and 39 with other pathologies (the control group). There were 21 patients in the control group with a diagnosis of cervical spondylotic myelopathy, and 18 with ossification of the posterior longitudinal ligament. All had plain lateral radiographs taken of the cervical spine as well as a reconstructed CT scan. The axial diameter of the width of the pedicle, the thickness of the lateral mass, the height of the isthmus and internal height were measured. The transverse diameter of the transverse foramen (d1) and that of the spinal canal (d2) were measured, and the ratio $\mathrm{d} 1 / \mathrm{d} 2$ calculated.

The width of the pedicles and the thickness of the lateral masses were significantly less in patients with rheumatoid arthritis than in those with other pathologies. The area of the transverse foramina in patients with rheumatoid arthritis was significantly greater than that in the other patients. The ratio of $\mathrm{d} 1$ to $\mathrm{d} 2$ was not significantly different. A high-riding vertebral artery was noted in $33.9 \%$ of the patients with rheumatoid arthritis and in $\mathbf{7 . 7} \%$ of those with other pathologies. This difference was statistically significant. In the rheumatoid group there was a significant correlation between isthmus height and vertical subluxation and between internal height and vertical subluxation.

Between $36 \%$ and $86 \%$ of patients with rheumatoid arthritis (RA) have some involvement of the cervical spine, ${ }^{1-3}$ and atlantoaxial subluxation is relatively common. ${ }^{4-9}$ Most of these patients can be managed conservatively, although operative treatment may be needed to treat progressive neurological impairment or radiographic instability. ${ }^{4-10}$ Chung et al ${ }^{11}$ have reported that the axis in patients with RA has a thinner isthmus and lateral mass than is found in other patients. Otherwise, the effects of RA on the anatomy of the cervical spine have not yet been fully explained.

Atlantoaxial transarticular screw fixation is a standard procedure for patients with atlantoaxial instability and provides rigid fixation and a high fusion rate. ${ }^{12,13}$ For patients whose cervical anatomy renders them unsuitable for this procedure, lateral mass fusion with a plate or screws may be used. ${ }^{14-16}$ Pedicle screw fusion has been used successfully in those with disease of the mid to lower cervical spine. ${ }^{17-19}$ It may be combined with atlantoaxial fusion to prevent progressive adjacent level instability, which is seen in some patients with RA. ${ }^{6-8,10}$ However, injury to the vertebral artery, spinal cord or nerve roots may occur because of the complex anatomy of the occipitocervical region. ${ }^{13,19-28}$ Consequently, pre-operative CT imaging is essential to avoid critical damage with its resultant complications. ${ }^{24,29-32}$

The purpose of this study was to identify the anatomical variation that occurs in female patients with RA. We felt that this information would help to prevent the complications and poor outcomes that can occur with this type of surgery.

We concentrated on females, as RA is eight times more prevalent in women than men. ${ }^{33}$

\section{Materials and Methods}

Between April 2004 and September 2007, 129 women had plain lateral radiographs and reconstructed CT scans of the whole cervical spine taken at our university hospital. The patients fell into two groups: 90 with RA and 39 with other pathologies.

The mean age of those with RA were 62.7 years (23 to 86 ). The diagnosis of RA was confirmed by a rheumatologist (SN). Each patient had a history of RA for more than two years ( 2 to 43 ) and no clinical history of major cervical trauma. Four of the patients with RA had previously undergone a posterior atlantoaxial fusion. 


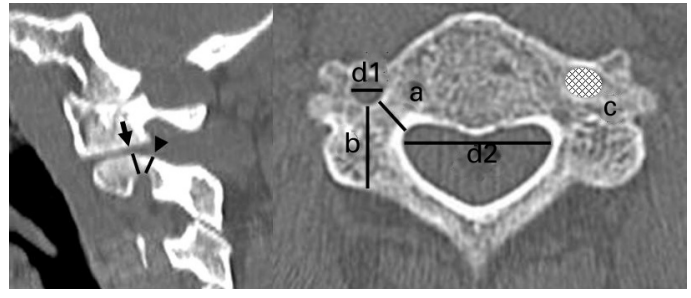

Fig. 1

The measurement of isthmus height (arrowhead) and internal height (arrow) on sagittal reconstructed CT images. The pedicle isthmus width (a) was measured from C2-7. The distance of the lateral mass thickness (b) was measured from the posterior cortex to the posterior edge of the transverse foramen. The areas of the transverse foramina were measured; black mesh circle (c). The transverse diameter of transverse foramina (d1) and the transverse diameter of spinal canal (d2) were measured, and the ratio $\mathrm{d} 1 / \mathrm{d} 2$ calculated.

The mean age of the 39 women with other pathologies was 60.7 years ( 38 to 83 ). Of these, 21 had a diagnosis of cervical spondylotic myelopathy and 18 had ossification of the posterior longitudinal ligament. This group of 'controls' was somewhat biased by these diagnoses and probably differed significantly from a general population of agematched patients. However, they were the best that were available to us. Normal subjects were impossible to recruit because of the need for CT scans and radiographs.

Scanning protocol. Atlantoaxial subluxation and superior migration of the odontoid process were both measured from lateral radiographs. ${ }^{34}$ The atlantodental interval was measured from dynamic lateral radiographs. Vertical subluxation was measured using the methods described by Ranawat and Redlund-Johnell and Pettersson. ${ }^{4,34,35}$ The CT scans were obtained using a multislice scanner (Siemens Medical Solutions, Erlangen, Germany). Image data were obtained in $1 \mathrm{~mm}$ slices, reconstructed by the highresolution kernel and transferred onto digital software (Aquarius NET Server, Terarecon Inc, Tokyo, Japan).

The software generated three-dimensional orthogonal (axial, sagittal and coronal) scans and synchronised with multiplane. A midline sagittal and axial reconstruction of the atlantoaxial facet joint was performed with validation of the trajectory through the C1-2 transarticular screw. Placement of the C1-2 transarticular screw was virtually determined by the software. A high-riding vertebral artery was defined as an internal height of the axis $<2 \mathrm{~mm}$, and an isthmus height $<5 \mathrm{~mm}$ on the reconstructed CT images. ${ }^{36}$ Axial images were obtained of the isthmus of the pedicle, and its outer width was measured from C2-7 (Fig. 1). The thickness of the lateral mass was measured from its posterior cortex to the posterior edge of the transverse foramen. The areas of the left and right transverse foramina were measured. The transverse diameter of the right and left transverse foramina $(\mathrm{d} 1)$ and the transverse diameter of the spinal canal $(\mathrm{d} 2)$ were measured, and a ratio $\mathrm{d} 1 / \mathrm{d} 2$ calculated. Two orthopaedic surgeons (KH, TE) analysed the data independently.

Statistical analysis. The demographics of the patients with RA were compared with those of other pathologies. The anatomical difference in isthmus height and internal height of the lateral mass, and the difference in the incidence of a high-riding vertebral artery between the RA group and the controls were compared using the Mann-Whitney $U$ test and the chi-squared test for independence. Means and SD were calculated for all dimensions of the pedicle and the thickness of the lateral mass. The distribution of these was then plotted for each cervical level. The relationship between a high-riding vertebral artery and atlantoaxial subluxation of the cervical spine (atlantodental interval $(\mathrm{ADI}))^{4,34,35}$ was investigated using Pearson's correlation coefficient. Regression analysis was performed using simple regression. All statistical analyses were performed using StatView, version 5.0 (Abacus Concepts, Berkeley, California) with $\mathrm{p}<0.05$ considered statistically significant.

\section{Results}

The demographic data for all patients are shown in Table I. There was no significant difference in age or height between the two groups. The lateral radiographs of the cervical spine in the patients with RA showed significant abnormalities in terms of both atlantoaxial and vertical subluxation. Pedicle width. The mean pedicle widths from $\mathrm{C} 2-7$ in patients with RA were significantly less than those in the control group (Fig. 2). It was $<3.5 \mathrm{~mm}$ in 107 of 1080 pedicles $(9.9 \%)$ in the patients with RA (C2 26; C3 32; C4 27; C5 13; C6 9), whereas in the control group it was $<3.5 \mathrm{~mm}$ in eight of 468 pedicles (1.7\%) (C2 1; C3 2; C4 3; C5 1; C6 1).

Lateral mass thickness. From $\mathrm{C} 3-7$, the mean thicknesses of the lateral masses in the patients with RA were significantly less than those in the control group (Fig. 2). It was $<9 \mathrm{~mm}$ in 71 of 900 lateral masses $(7.9 \%)$ in the patients with RA (C3 14; C4 9; C5 2; C6 9; C7 37), whereas in the control group it was $<9 \mathrm{~mm}$ in 12 of 390 lateral masses $(3.1 \%)(\mathrm{C} 32$; C4 1; C6 1; C7 8).

Area of transverse foramen. The mean areas of the transverse foramina from C1-5 in the patients with RA were significantly greater than that in the control group (Fig. 3). On the other hand, the ratio of $\mathrm{d} 1 / \mathrm{d} 2$ was not significantly different at any level between C1 and C5 (Fig. 3).

High-riding vertebral artery. There were significant differences in the mean isthmus heights and the mean internal heights between the RA patients and the control group. A high-riding vertebral artery was present in $33.9 \%$ (61 of 180 joints) of the RA patients and in $7.7 \%$ (6 of 78 joints) of the controls: this difference was significant (Table I).

A statistically significant positive correlation was observed between isthmus height and vertical subluxation in the patients with RA as measured by the Ranawat $(\mathrm{R}=0.312, \mathrm{p}<0.0001)$ and the Redlund-Johnell method $(\mathrm{R}=0.369, \mathrm{p}<0.0001)$. A statistically significant positive 
Table I. The demographic data and measurements of the 129 patients; 90 had rheumatoid arthritis (RA). The other 39 patients consisted of 21 with cervical spondylotic myelopathy and 18 with ossification of the posterior longitudinal ligament

\begin{tabular}{|c|c|c|c|c|}
\hline & Total & RA & Other pathologies & p-value \\
\hline Patients & 129 & 90 & 39 & \\
\hline Mean age years (range) & 61.8 (23 to 86$)$ & 62.3 (23 to 86$)$ & 60.7 (38 to 81$)$ & $0.3811^{\dagger}$ \\
\hline Mean height in $\mathrm{cm}$ (range) & $152.4(122$ to 165$)$ & $152.4(122$ to 165$)$ & $152.8(137$ to 165$)$ & $0.7888^{\dagger}$ \\
\hline Mean weight (range) & 54.2 (30 to 84$)$ & 52.5 (30 to 84$)$ & 61.9 (43 to 80$)$ & 0.007 \\
\hline \multicolumn{5}{|l|}{ Radiographs (mm) } \\
\hline $\mathrm{ADI}^{*}$ mean $(\mathrm{SD})$ & & $4.4(3.2)$ & $1.9(1.1)$ & $0.0001^{\dagger}$ \\
\hline Ranawat mean (SD) & & $13.7(3.4)$ & $14.8(3.4)$ & $0.0001^{\dagger}$ \\
\hline Redlund-Johnell mean (SD) & & $33.3(6.2)$ & $36.1(4.9)$ & $0.0001^{\dagger}$ \\
\hline Isthmus height (SD) & & $6.3(3.0)$ & $8.1(2.2)$ & $0.0001^{\dagger}$ \\
\hline Internal height (SD) & & $6.0(3.2)$ & $7.8(3.3)$ & $0.0001^{\dagger}$ \\
\hline High-riding vertebral artery (\%) & & $61.0(33.9)$ & $6.0(7.7)$ & $0.0001^{\ddagger}$ \\
\hline Mean history of RA (yr) & & 14.8 & & \\
\hline
\end{tabular}

${ }^{*} \mathrm{ADI}$, atlantodental interval

$\dagger$ Mann-Whitney U-test, $\alpha=0.05$

¥ chi-squared test for independence, $\alpha=0.05$
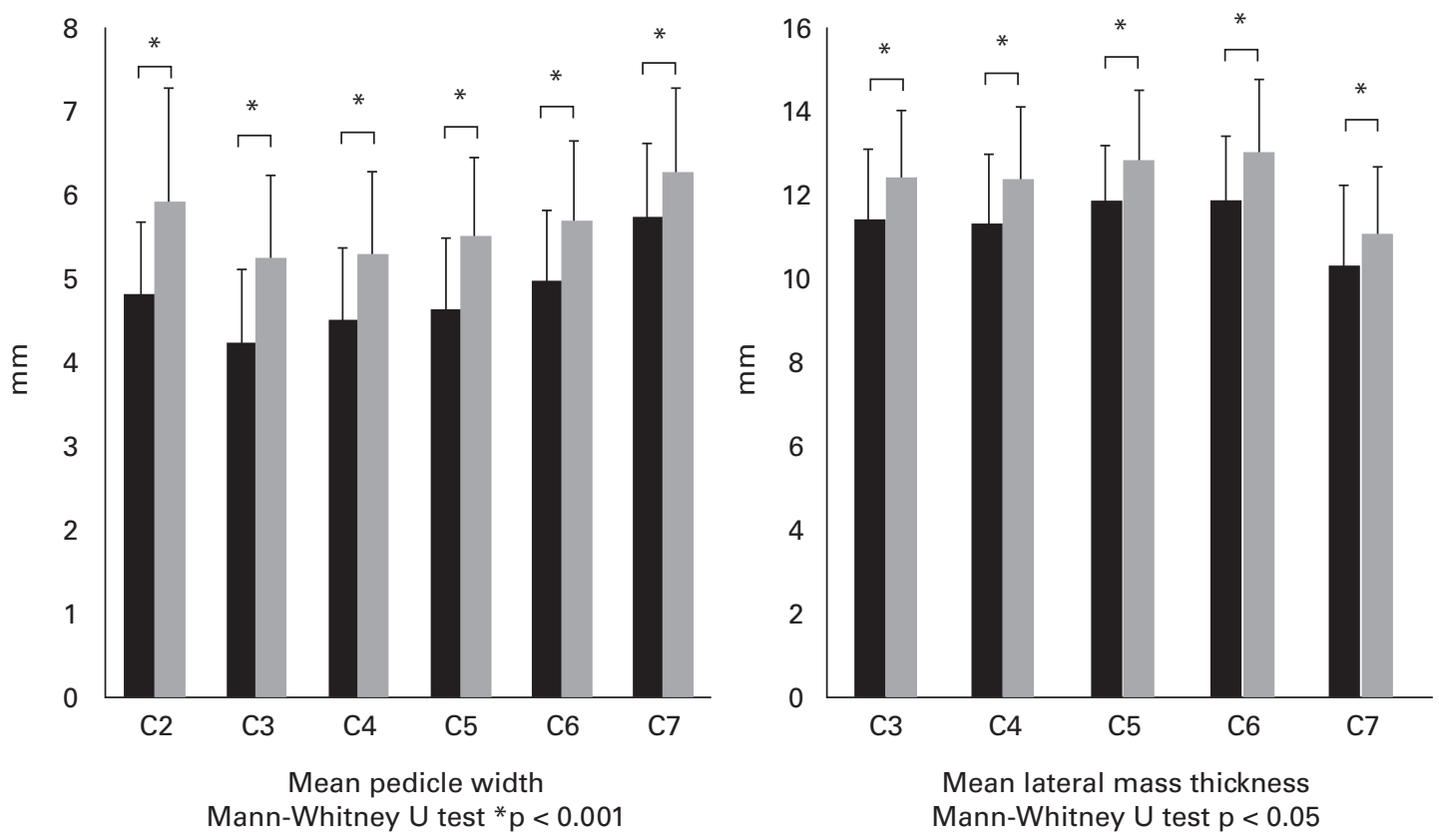

Fig. 2

Bar charts showing that the mean pedicle widths and lateral mass thicknesses of 90 women with rheumatoid arthritis (RA) were significantly less than those of the 39 patients with other pathologies (black bars = RA, open bars = other pathologies).

correlation was also observed between the internal height and vertical subluxation as measured by the Ranawat $(\mathrm{R}=0.310, \mathrm{p}<0.0001)$ and the Redlund-Johnell method $(\mathrm{R}=0.310, \mathrm{p}<0.0001)$ (Fig. 4). There was a significant negative correlation between isthmus height and the atlantodental interval, and a significant negative correlation between isthmus height $(\mathrm{Y}=-0.167 \mathrm{X}+5.552$,
$\mathrm{R}=-0.157, \mathrm{p}<0.0001)$ and a history of RA $(\mathrm{Y}=-0.754 \mathrm{X}$ $+19.545, \mathrm{R}=-0.235, \mathrm{p}<0.0001)$ in the patients with RA. In each patient there was a significant difference in isthmus height and internal height between the two sides. The mean isthmus heights on the right and left sides were $7.4 \mathrm{~mm}$ and $6.2 \mathrm{~mm}$, respectively. The mean internal heights of the right and left sides were $7.6 \mathrm{~mm}$ and $5.4 \mathrm{~mm}$, 


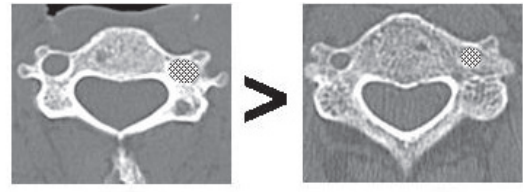

RA

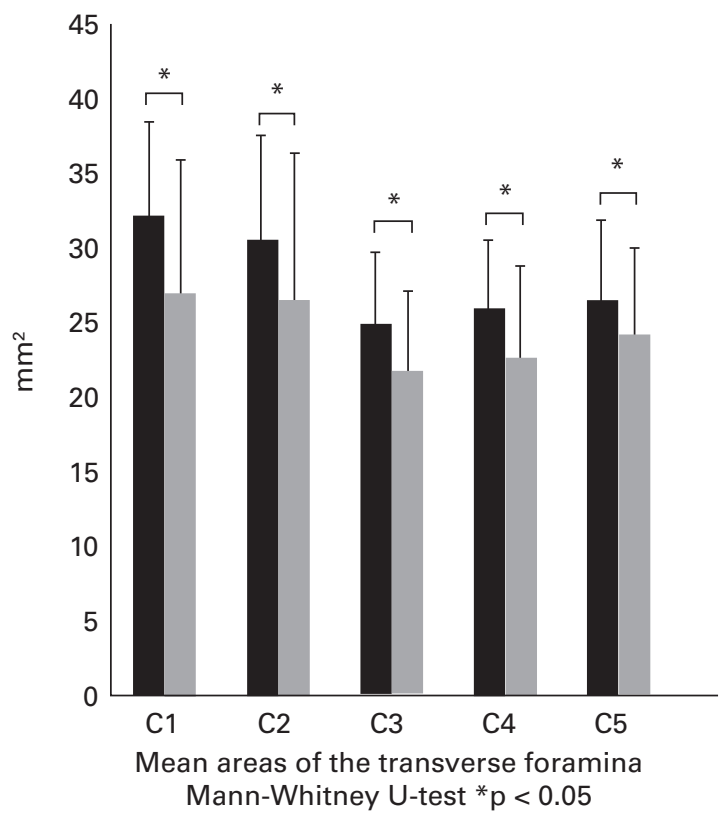

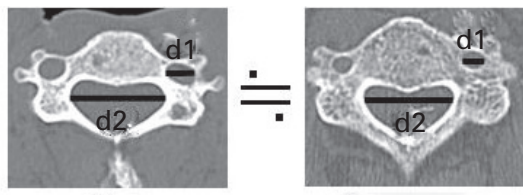

RA

non-RA

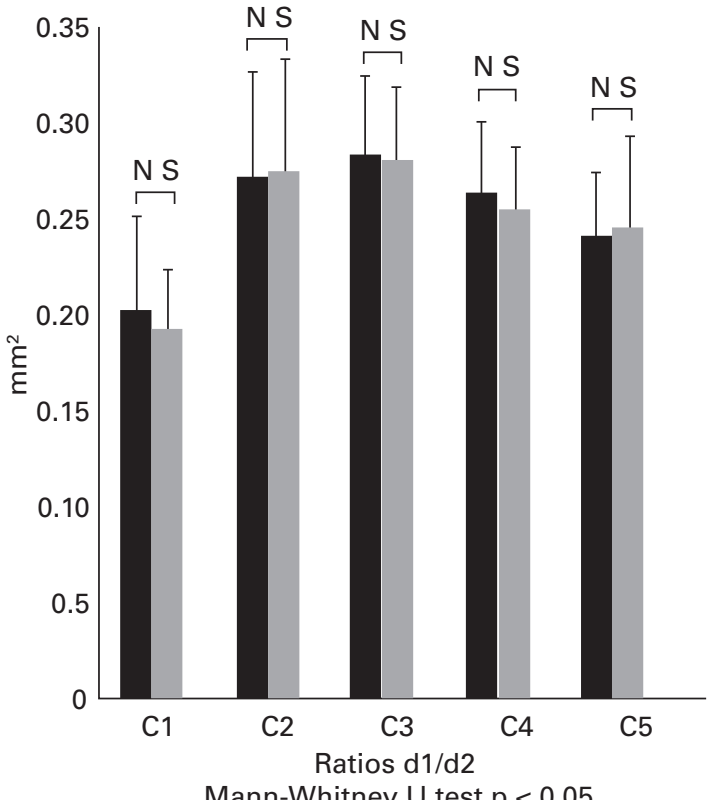

Mann-Whitney U test $\mathrm{p}<0.05$

Fig. 3

Bar charts showing that the mean areas of the transverse foramina (' $c$ ' in Fig. 1) from $\mathrm{C} 1-5$ in the patients with rheumatoid arthritis (RA) were significantly greater than those with other pathologies. The ratios d1/d2 from C1-5 were not significantly different when the patients with RA were compared with the others (black bars $=\mathrm{RA}$, open bars $=$ other pathologies).

respectively. A high-riding vertebral artery was apparent in $25(9.7 \%)$ joints on the right and $42(16.3 \%)$ on the left.

\section{Discussion}

The most important results to come from this comparison between women with RA and those with other pathologies are: 1) the mean pedicle widths and thickness of the lateral mass in the patients with RA were significantly less than those with other pathologies; 2 ) the mean area of the transverse foramen from C1-5 in the patients with RA was significantly greater than that in those with other pathologies; on the other hand, the ratio of $\mathrm{d} 1 / \mathrm{d} 2$ was not significantly different at any level from C1-5; 3) a high-riding vertebral artery was present in $33.9 \%$ of the patients with RA and $7.7 \%$ in those with other pathologies: this difference was significant; 4) a statistically significant correlation was observed between isthmus height and vertical subluxation in the patients with RA.

Previous studies have shown that a high-riding vertebral artery was present in $13 \%$ to $23 \% .^{10,27,36}$ Chung et al ${ }^{11}$ reported that a high-riding vertebral artery was present in $54 \%$ ( 15 of 28 joints, 9 of 14 patients) of patients with RA and in $12 \%$ ( 3 of 26 joints, 2 of 13 patients) of those without. The isthmus and internal heights of the axis in women with RA were statistically significantly less than those in the female control group. Simple regression analysis showed a correlation between isthmus height and vertical subluxation as well as a correlation between the internal height and vertical subluxation. There was a significant correlation between isthmus height and the width of the atlantodental interval. RA causes a loss of tensile strength and stretching of the transverse and alar ligaments, which in turn causes atlantoaxial and vertical subluxation. ${ }^{37-39}$ Our study shows that vertical subluxation shows a positive correlation with a lowering of isthmus height as well as a high-riding vertebral artery.

It is unclear from previous studies whether there is bilateral symmetry of high-riding vertebral arteries. ${ }^{27,29,36}$ Our data show that there are significant differences between the left and right sides, with the left more likely to have a high-riding vertebral artery. Thus, in a patient with a high-riding vertebral artery on the left, transarticular screw fixation could be a better procedure for the right side, whereas the left would be suitable for posterior wiring. ${ }^{10,11,29,36}$ 

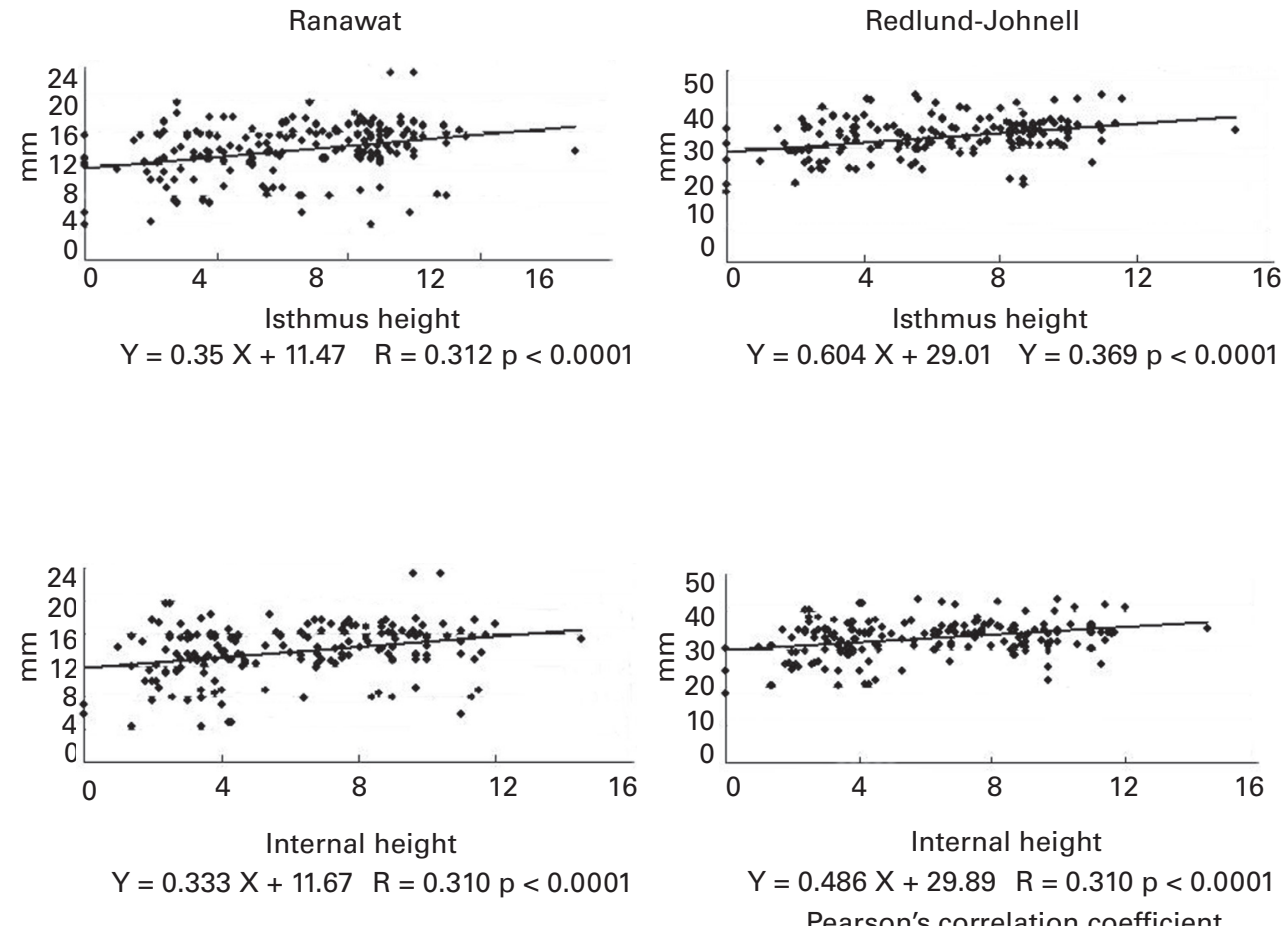

Fig. 4

Graphs showing statistically significant correlations with simple regression analysis were observed between isthmus and length, and between internal height and length in 90 patients with rheumatoid arthritis measured using the methods of Ranawat ${ }^{4}$ and Redlund-Johnell. ${ }^{34,35}$

Several of the patients with RA had an enlarged transverse foramen, which may conceivably have housed a tortuous vertebral artery. ${ }^{20,28}$ The mean area of the transverse foramen in the patients with RA was significantly greater than that in those with other pathologies. However, the ratio of the width of the spinal canal to the transverse diameter of the transverse foramen was not significantly different between the two groups. This suggests that thinning of both the width of the pedicle and the thickness of the lateral mass in the patients with RA, caused by loss of bone from both sides (i.e. the transverse foramen and the spinal canal), is the result of RA.

Multiplanar reconstructed CT can provide an accurate image of the course of the vertebral artery. This study provides additional morphological data from a large number of women with RA and other pathologies. It is also the first to show that both the width of the pedicle and the thickness of the lateral mass in patients with RA are less than in those with other pathologies, and that a high-riding vertebral artery occurs with vertical subluxation. This adds to our understanding of the effect of RA on the cervical spine.

No benefits in any form have been received or will be received from a commercial party related directly or indirectly to the subject of this article.

\section{References}

1. Mathews JA. Atlanto-axial subluxation in rheumatoid arthritis. Ann Rheum Dis 1969;28:260-6.

2. Pellicci PM, Ranawat CS, Tsairis $\mathbf{P}$, Bryan WJ. A prospective study of the progression of rheumatoid arthritis of the cervical spine. J Bone Joint Surg [Am]1981;63A:342-50.

3. Ornilla E, Ansell BM, Swannell AJ. Cervical spine involvement in patients with chronic arthritis undergoing orthopaedic surgery. Ann Rheum Dis 1972;31:364-8.

4. Ranawat CS, O'Leary $\mathbf{P}$, Pellicci $\mathbf{P}$, et al. Cervical spine fusion in rheumatoid arthritis. J Bone Joint Surg [Am] 1979;61-A:1003-10.

5. Crockard HA, Essigman WK, Stevens JM, et al. Surgical treatment of cervical cord compression in rheumatoid arthritis. Ann Rheum Dis 1985;44:809-16.

6. Redlund-Johnell I, Pettersson H. Subaxial antero-posterior dislocation of the cervical spine in rheumatoid arthritis. Scand J Rheumatol 1985;14:355-63.

7. Zoma A, Sturrock RD, Fisher WD, Freeman PA, Hamblen DL. Surgical stabilisation of the rheumatoid cervical spine: a review of indications and results. J Bone Joint Surg [Br] 1987;69-B:8-12.

8. Santavirta S, Konttinen YT, Laasonen E, et al. Ten-year results of operations for rheumatoid cervical spine disorders. J Bone Joint Surg [Br] 1991;73-B:116-20.

9. Clarke MJ, Cohen-Gadol AA, Ebersold MJ, Cabanela ME. Long-term incidence of subaxial cervical spine instability following cervical arthrodesis surgery in patients with rheumatoid arthritis. Surg Neurol 2006;66:136-40.

10. Papadopoulos SM, Dickman CA, Sonntag VK. Atlantoaxial stabilization in rheumatoid arthritis. J Neurosurg 1991;74:1-7.

11. Chung SS, Lee CS, Chung HW, Kang CS. CT analysis of the axis for transarticular screw fixation of rheumatoid atlantoaxial instability. Skeletal Radio/ 2006;35:679-83.

12. Dickman CA, Sonntag VK. Posterior C1-C2 transarticular screw fixation for atlantoaxial arthrodesis. Neurosurgery 1998;43:275-80.

13. Naderi S, Crawford NR, Song GS, Sonntag VK, Dickman CA. Biomechanical comparison of C1-C2 posterior fixations: cable, graft, and screw combinations. Spine 1998;23:1946-55 
14. Goel A, Laheri V. Plate and screw fixation for atlanto-axial subluxation. Acta Neurochir (Wien) 1994;129:47-53.

15. Harms J, Melcher RP. Posterior C1-C2 fusion with polyaxial screw and rod fixation Spine 2001;26:2467-71.

16. Horn EM, Hott JS, Porter RW, et al. Atlantoaxial stabilization with the use of C1 3 lateral mass screw fixation: technical note. J Neurosurg Spine 2006;5:172-7.

17. Abumi K, Itoh H, Taneichi H, Kaneda K. Transpedicular screw fixation for traumatic lesions of the middle and lower cervical spine: description of the techniques and preliminary report. J Spinal Disord 1994;7:19-28.

18. Abumi K, Kaneda K. Pedicle screw fixation for nontraumatic lesions of the cervical spine. Spine 1997;22:1853-63.

19. Abumi K, Shono Y, Ito $\mathbf{M}$, et al. Complications of pedicle screw fixation in reconstructive surgery of the cervical spine. Spine 2000;25:962-9.

20. Coric D, Branch CL Jr, Wilson JA, Robinson JC. Arteriovenous fistula as a complication of C1-2 transarticular screw fixation: case report and review of the literature. J Neurosurg 1996;85:340-3.

21. Goel A, Gupta S. Vertebral artery injury with transarticular screws. J Neurosurg 1999;90:376-7.

22. Marcotte P, Dickman CA, Sonntag VK, Karahalios DG, Drabier J. Posterio atlantoaxial facet screw fixation. J Neurosurg 1993;79:234-7.

23. Wright NM, Lauryssen C. Vertebral artery injury in C1-2 transarticular screw fixation: results of a survey of the AANS/CNS section on disorders of the spine and peripheral nerves: American Association of Neurological Surgeons/Congress of Neurological Surgeons. J Neurosurg 1998;88:634-40.

24. Kast E, Mohr K, Richter HP, Borm W. Complications of transpedicular screw fixation in the cervical spine. Eur Spine J 2006;15:327-34.

25. Hong JT, Lee SW, Son BC, et al. Hypoglossal nerve palsy after posterior screw placement on the C-1 lateral mass: case report. J Neurosurg Spine 2006;5:83-5.

26. Neo M, Fujibayashi S, Miyata M, Takemoto M, Nakamura T. Vertebral artery injury during cervical spine surgery: a survey of more than 5600 operations. Spine 2008;33:779-85
27. Neo M, Matsushita M, Iwashita Y, et al. Atlantoaxial transarticular screw fixation for a high-riding vertebral artery. Spine 2003;28:666-70

28. Paramore CG, Dickman CA, Sonntag VK. The anatomical suitability of the C1-2 complex for transarticular screw fixation. J Neurosurg 1996;85:221-4.

29. Song GS, Theodore N, Dickman CA, Sonntag VK. Unilateral posterior atlantoaxial transarticular screw fixation. J Neurosurg 1997;87:851-5.

30. Chazono M, Soshi S, Inoue T, Kida Y, Ushiku C. Anatomical considerations for cervical pedicle screw insertion: the use of multiplanar computerized tomography reconstruction measurements. J Neurosurg Spine 2006;4:472-7.

31. Nogueria-Barbosa MH, Defino HL. Multiplanar reconstructions of helical computed tomography in planning of atlanto-axial transarticular fixation. Eur Spine $J$ 2005; 14:493-500.

32. Sakamoto T, Neo M, Nakamura T. Transpedicular screw placement evaluated by axial computed tomography of the cervical pedicle. Spine 2004;29:2510-14.

33. Jawaheer D, Lum RF, Gregersen PK, Criswell LA. Influence of male sex on disease phenotype in familial rheumatoid arthritis. Arthritis Rheum 2006;54:3087-94.

34. Hinck VC, Hopkins CE. Measurement of the atlanto-dental interval in the adult. Am J Roentgenol Radium Ther Nucl Med 1960;84:945-51.

35. Redlund-Johnell I, Pettersson H. Radiographic measurements of the craniovertebral region: designed for evaluation of abnormalities in rheumatoid arthritis. Acta Radiol Diagn (Stockh) 1984;25:23-8.

36. Bloch 0, Holly LT, Park J, et al. Effect of frameless stereotaxy on the accuracy of C1-2 transarticular screw placement. J Neurosurg 2001;95(Suppl):74-9.

37. Ball J, Meijers KA. On cervical mobility. Ann Rheum Dis 1964;23:429-38.

38. Ball J, Sharp J. Rheumatoid arthritis of the cervical spine. Mod Trends Rheumatol 1971;2:117-38.

39. Martel W. Pathogenesis of cervical discovertebral destructions in rheumatoid arthritis. Arthritis Rheum 1977:20:1217-25. 